\title{
Cost Effectiveness of Emollients in the Prevention of Relapses in Atopic Dermatitis
}

This article was published in the following Dove Press journal:

Clinical, Cosmetic and Investigational Dermatology

\section{Elise Cabout $\mathbb{D}^{1}$ \\ Sebastien Eymere $\mathbb{D}^{\prime}$ \\ Robert Launois (1D) \\ Flavia Aslanian $\mathbb{D}^{2}$ \\ Charles Taïeb (iD ${ }^{3,4}$ \\ Sophie Seité (iD ${ }^{5}$}

'Réseau d'évaluation en Économie de la Santé (REES), Paris, France; ${ }^{2}$ Epsom and St Helier University Hospitals NHS Trust, London, UK; ${ }^{3}$ EMMA, Fontenay-sousBois, France; ${ }^{4}$ Hôpital Necker EnfantsMalades, Santé Publique, Paris, France; ${ }^{5}$ La Roche-Posay Dermatological Laboratories, Levallois-Perret, France
Correspondence: Sophie Seité La Roche-Posay Dermatological Laboratories, 62 Quai Charles Pasqua, Levallois-Perret 92300 , France

Tel +33 I 49643340

Email sophie.seite@loreal.com
Introduction: Atopic dermatitis (AD) is chronic inflammatory skin condition, characterized by its remission-relapse cycles. This predominantly pediatric disease is becoming more and more prevalent. Emollients are part of the therapeutic management and particularly a way to increase time between relapses. The follow-up of $\mathrm{AD}$ and relapses have a great impact on patient's quality of life, expenditures and society costs. The aim of this study is to assess the cost-effectiveness of different emollients prescribed to AD patients.

Methods: A three-state Markov simulation model was developed over a six-year period with 28 days cycles. Two perspectives were adopted, a health care system perspective and a societal perspective. Four different emollients (A, B, C, D) were compared with no emollient use. Time without flare-up was the key endpoint of the study. quality adjusted lifeyears (QALYs) were assessed as a secondary outcome. Cost and effectiveness data were derived from (i) randomized clinical trials and literature review for the efficacy of treatments, (ii) resource utilization and quality of life data, and (iii) unit prices from official price lists. Results: The six-year health care costs associated with emollient A amount to $£ 1844.23$ and generate 4.58 years-without flare-up. Compared to emollient $\mathrm{B}$, emollient $\mathrm{A}$ is costlier $(\Delta$ $£ 41)$ but more effective ( 0.097 years). The ICER is $£ 428.30$ per year without flare-up. Emollient $\mathrm{A}$ is the dominant strategy compared to no treatment $(£ 2,251.01 ; 3.99$ years without flare-ups). When accounting for the societal costs, emollient $\mathrm{A}$ is the dominant strategy.

Discussion: According to the analysis, treatment with preventive emollient was a costeffective option compared with no treatment in adult $\mathrm{AD}$ patients. In this comparative study, emollient $\mathrm{A}$ is the most efficient strategy from a willingness to pay $£ 200$ with a probability of $49 \%$.

Keywords: atopic dermatitis, cost-effectiveness, Markov model

\section{Introduction}

Atopic dermatitis (AD) is an inflammatory skin condition affecting between 5 and $20 \%$ of children. ${ }^{1}$ This disease mostly recovers by itself at adulthood in $85 \%$ of cases. In industrialized countries, prevalence of AD has tripled in the last 30 years. Given the air pollution, incidence will not decrease, and this disease will continue to be a burden.

$\mathrm{AD}$ is a chronic, remitting-relapsing, pruritic, inflammatory, immune-mediated skin condition. Skin may be red and inflamed (erythema), thickened and leathery (lichenification) and dry (xerosis) with scaly plaques, bleeding, oozing, cracking and flaking. Itching (pruritus) is the most disruptive symptom. It may be unrelenting, frequent and intense, affecting sleep and causing anxiety or depression. ${ }^{2}$ 
Itching may also affect work performances and learning abilities having a tremendous impact on one's quality of life.

$\mathrm{AD}$ is characterized by its relapse-flare-up cycle: a period nearly symptom free is followed by an acute inflammatory flare-up where the patient needs to use corticoids to soothe the inflammation.

$\mathrm{AD}$ relapses are prevented by the daily use of moisturiser. $^{3-5}$ Thus, NICE recommends moisturisers as the first-line of treatment in delaying flare-ups, and corticoids to treat acute phases. ${ }^{6}$ Nevertheless, this therapy aims only to manage the symptoms. It improves quality of life by decreasing the frequency and the intensity of flare-ups, the number of visits to a doctor, and the loss of productivity.

The scoring of atopic dermatitis (SCORAD), is an assessment tool of AD. It combines extent, severity and subjective symptoms of the disease. This tool is used by physicians to determine whether a treatment, in our case an emollient, has been effective in soothing AD symptoms.

While a collection of emollient floods the market, their efficiency is not well known. To our knowledge few costeffectiveness studies have been published and none were comparing an overall set of emollients. ${ }^{7,8}$

The aim of the study is to assess the cost-effectiveness of four emollients (A, B, C, D) on $\mathrm{AD}$ relapses. It will consider the health results as well as the cost of intervention for the health system.

\section{Methods}

A cost effectiveness study was design. Two dermocosmetic emollients (A and D) are compared to a massmarket emollient (emollient B), to an emollient medical device (MD) (C) and to no emollient (composition of emollients (INCI) in supporting information). The base case scenario was completed with deterministic sensitivity analyses (DSA), probabilistic sensitivity analysis (PSA) and scenario analyses.

All statistical analyses were performed using Microsoft Excel version 16.0 for Office 365 .

\section{Analytical Framework}

The model was based on patients' data extracted from a randomized controlled trial (RCT). ${ }^{9}$ Ninety-nine patients aged six months and older with mild AD were recruited in this trial. The mean age was $11.5 \pm 12.6$ years old. $26.3 \%$ of them were aged 16 and more. More than half (56.6\%) were female, reflecting the sex ratio of the disease.
Population from other RCT's similarity regarding age and sex was assessed. As no differences were found between populations, patients were modelled from this RCT. $^{9}$

As $\mathrm{AD}$ is a chronic disease, a three states Markov model was implemented to mimic the course of the disease: "flare-ups", "postcorticoid", "maintenance" (Figure 1). Patients in the maintenance or postcorticoid states are considered to have mild AD according to their SCORAD score and moderate AD when they are in the flare-up state - this stage is defined by a degradation of SCORAD score $>20 \%$.

Modelled patients enter the model in the postcorticoid stage. In this stage: either the patient can relapse, or they can enter the maintenance stage. Once the patient enters the flare-up stage it is assumed that the patient will use corticosteroids, at the end of the cycle the patient will automatically transition to the postcorticoid stage.

A literature review from van Zuuren et $\mathrm{al}^{5}$ reported 15 RCTs assessing survival before flare-ups. The authors assessed quality of the study as well according to their risk of selection bias, detection bias, attrition bias, and reporting bias. Using data from this review we defined transition probabilities. When the RCT lasted for a different time frame than the published $\mathrm{RCT}^{9}{ }^{9}$ we used the DEALE (Declining Exponential Approximation of Life Expectancy) method ${ }^{10}$ to compute transition probabilities.

The main assumption in the construction of this model is the equality of the transition probabilities between the maintenance state and the flare-up state (Mf) and between the postcorticoid state and the flare-ups state (Pf). Thus the three health states model could be assimilated to a two health states model, similar to the one found in the literature. $^{7,8}$ However, the three health state model is more comprehensive while integrating a seasonal effect, or a rebound effect. This hypothesis is motivated by the lack of data in the literature, which mention only the Pf probabilities. The heterogeneity of patient care according to the severity of AD led to the adoption of this assumption with support of expert opinion. While there is evidence of seasonal reductions of flare-up probability during the summer this reduction has not been quantified yet. Therefore, we could not take it into account in the model (Table 1).

Four moisturisers were compared. INCI (International Nomenclature of Cosmetic Ingredients) composition of different comparators are available in supporting information. 


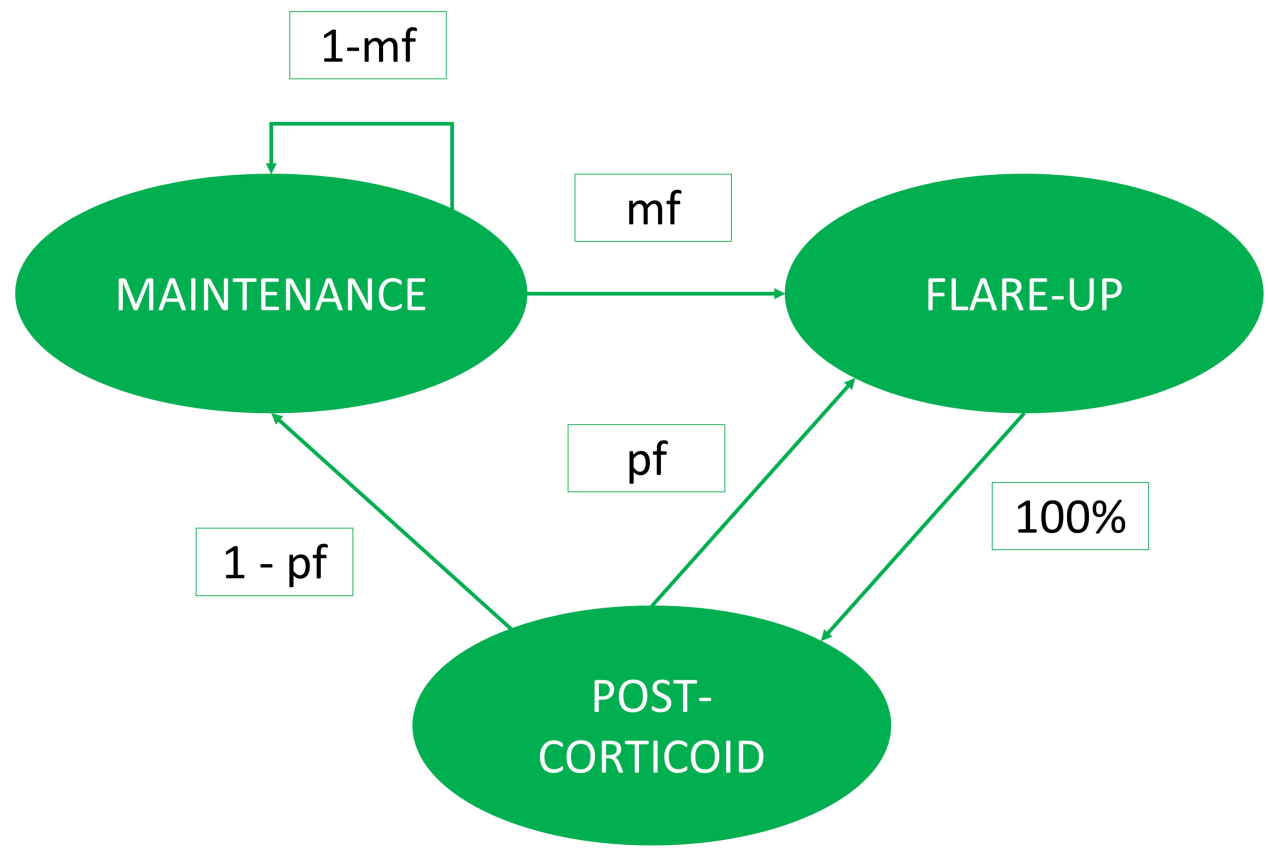

Figure I Markov model used to model cost-efficiency of different emollients.

Notes: Pf, probability to enter the flare-up state from the postcorticoid state; I-Pf, probability to enter the maintenance state from the postcorticoid state; Mf, probability to enter the flare-up state from the maintenance state; I-Mf, probability to stay in the maintenance state.

Emphasis will be put on comparison of the most effective emollient (A) to a mass-marketed emollient (B) and no treatment options. Nevertheless, two other emollients, an emollient MD status (C) and another dermocosmetic (D) were used in the comparison.

A six-year time horizon was selected for the base-case scenario. A meta-analysis reported a mean duration of AD persistence of 6.1 years. ${ }^{11}$ The studied population will consist of adults and children. Hence, we must consider that the treatment will not be taken for life. The RCT used to model the transition probabilities lasted for four weeks or 28 days, consequently we chose to use cycle of 28 days. A half cycle correction was applied. ${ }^{12}$

Table I Transition Probabilities

\begin{tabular}{|c|c|c|}
\hline Emollient & Conversion Method & Mf \\
\hline Emollient $A^{9}$ & $\begin{array}{l}\text { Directly from the Kaplan-Meier } \\
\text { curve of RCT }\end{array}$ & $18.00 \%$ \\
\hline No moisturiser ${ }^{16}$ & DEALE & $35.73 \%$ \\
\hline Emollient $\mathrm{B}^{16}$ & DEALE & $20.56 \%$ \\
\hline Emollient $\mathrm{C}^{16}$ & DEALE & $28.38 \%$ \\
\hline Emollient $\mathrm{D}^{15}$ & $\begin{array}{l}\text { Directly from the Kaplan-Meier } \\
\text { curve of RCT }\end{array}$ & $32.00 \%$ \\
\hline
\end{tabular}

A discount rate of $3.5 \%$ was applied to efficacy and costs, following NICE recommendation. ${ }^{13}$

\section{Efficacy}

Efficacy of different treatments was derived from randomized controlled trials. ${ }^{9,14-16}$ Time without relapse was used as the marker of effectiveness. Time without relapse was defined as the time each patient spent in a different state than flare-up. ECLA study reports a utility of 0.79 for mild AD, and 0.68 for moderate AD. ${ }^{18}$ These utilities will be used in the model to compute the efficacy of treatments in a complementary analysis. Time without relapse was deemed more appropriate for the study of AD than quality adjusted life-years (QALY). Indeed, while QALY are a great tool to measure the impact on the medical quality of life, time without flare-up describes more accurately the daily life of the patient, their comfort, and relationship toward the disease. Furthermore, using time without flare-up (TWFU) or years (YWFU) as a measure, we can only rely upon our model, without resorting to use an external clinical trial (ECLA study).

\section{Costs}

The costs used in the base-case model were the treatment costs: emollients, corticosteroids, hospitalization costs, follow-up costs (medical consultations) and other out-of-pocket 
expenditures. Due to the route of administration of the treatment, no administration costs were added.

It was impossible to use the NHS perspective, as the comparators are not all reimbursed yet by the public health insurance. Indubitably, it would have been questionable to exclude the costs of comparators in the comparisons. Therefore, a health system perspective was adopted. The health care system perspective includes all direct costs such as; treatment costs (both preventive and curative), consultations costs, hospitalization costs, and out-ofpocket expenditure specifically: clothes, bandages, hygiene products, sun protection, and food supplements. In the societal perspective we added an indirect cost of the disease in terms of productivity losses.

Prices were corrected for inflation using the health component of the Consumer Price Index. ${ }^{17}$ It was $2.91 \%$ from 2018 to 2019 and 5.24\% from 2017 to 2019. Cost of moisturisers was derived from NHS prescription cost analysis 2017 and 2018. ${ }^{18,19}$ Cost of treatment was obtained from the mean daily use of a moisturiser ${ }^{9,15,16}$ and its price (Table 2).

During flare-ups, treatment consists of application of topical corticosteroids. Åkerstrom et $\mathrm{al}^{20}$ reported a mean quantity of $5.9 \mathrm{~g}$ per application. Guidelines in good use of topical corticosteroid demands a total of 20 applications per cycle. To remain agnostic toward which steroid was used, the mean price weighted by the prescription rate of the top 10 topical corticosteroids used in the UK was computed from the NHS prescription cost analysis ${ }^{18,19}$ and a price of $£ 0.103 / \mathrm{mL}$ was used.

Beside the cost of treatment, other costs were included in the analysis. Other medical costs such as hospitalization and visit to different doctors (general practitioners (GPs) and/or specialists) were accounted for as well. Health-care utilization was extracted from the dupilumab appraisal; in flare-up state, on average a patient visits a GP 1.363 times, and a specialist in an outpatient visit 0.579 times. Costs were derived from personal social service, ${ }^{21}$ and national tariff payment. ${ }^{22}$

The ECLA study revealed that $1.80 \%$ of patients suffering from $\mathrm{AD}$ were fully hospitalized almost twice a year, and $0.40 \%$ were in a one-day hospitalization. ${ }^{23}$ Costs of hospitalization were derived from disease related groups: $\mathrm{AD}$ correspond to $\mathrm{JD} 07 \mathrm{~K}$ in the national tariff payment system and amounts to $£ 423$ a day (Table 3 ). ${ }^{22}$

The ECLA study showed that patients did not buy the same alleviating products: food supplements, cotton clothes, bandages, whether they were in mild or moderate $\mathrm{AD}$. It was used to estimate the out-of-pocket expenditure of patients suffering from AD (Table 4). ${ }^{24}$

In a complementary analysis, we changed the perspective and took all expenditure into account. We added the cost of productivity loss in a societal perspective. AD can lead to hospitalization and may impair work performance with the constant and debilitating itching. When the patient is a child, we assume that the productivity loss was from the caring parent who could not work while nursing their child. The ECLA study was used to assed the frequency of sickness leaves. The human capital method was used to account for the costs of productivity loss. We accounted both for sick leave in general and time spent in the physician's waiting room. ${ }^{25}$

\section{Results \\ Efficacy}

Emollient A is the most effective strategy as shown in Table 5. Patients using this emollient will have 4.58 years without flareup (YWFU) over a six-year period. It is 0.097 YWFU more than the emollient B and 0.60 YWFU more than no moisturiser. Although the difference is low, emollient $\mathrm{A}$ is more effective: 59.75 cycles in maintenance state, while it is $\mathbf{5 8 . 4 9}$ cycles for emollient B. These 1.26 cycles difference amounts to almost 35 days - improving the patient's quality of life. The difference between emollient $\mathrm{A}$ and no moisturiser is more than six months, $15 \%$ fewer flare-up cycles, improving greatly patients' quality of life.

These results are similar in the utility analysis. Emollient $\mathrm{A}$ is the most effective strategy. Utility under this treatment amounts to 4.19 QALY while emollient B to 4.18 QALY. Unsurprisingly the no moisturiser treatment

Table 2 Cost of Treatment

\begin{tabular}{|l|l|l|l|l|l|l|}
\hline Emollient & Daily Applications & Quantity/Application & g/Day & g/Cycle & Net Cost $\boldsymbol{f}^{\mathbf{1 8 , 1 9}}$ & Cost/Cycle $\boldsymbol{\epsilon}$ \\
\hline Emollient A & 2 & - & - & $191.60^{9}$ & 0.0311 & \\
Emollient B & 2 & $5.35^{16}$ & 10.7 & 299.6 & 0.0121 & 6.27 \\
Emollient C & 3 & $5.6875^{16}$ & 17.0625 & 477.75 & 0.1246 & 3.81 \\
Emollient D & 2 & $5.6875^{15}$ & 11.375 & 318.5 & 0.0317 & 62.67 \\
Corticosteroids & $0.71^{20}$ & 5.9 & & 118 & 0.1079 & 10.63 \\
\hline
\end{tabular}


Table 3 Resources and Value

\begin{tabular}{|c|c|c|c|c|}
\hline $\begin{array}{l}\text { Health } \\
\text { Consumption }\end{array}$ & $\begin{array}{l}\text { Mean/ } \\
\text { Year }\end{array}$ & $\begin{array}{l}\text { Frequence } \\
\text { of Patients }\end{array}$ & Value & $\begin{array}{l}\text { Cost } \\
t\end{array}$ \\
\hline $\begin{array}{l}\text { Standard } \\
\text { hospitalization } \\
\text { in patient with } \\
\text { mild } A D\end{array}$ & 2 & $1.80 \%$ & $\begin{array}{l}\text { Healthcare } \\
\text { Resource } \\
\text { Group JD07K }\end{array}$ & 423.00 \\
\hline $\begin{array}{l}\text { Day } \\
\text { hospitalization } \\
\text { in patient with } \\
\text { mild AD }\end{array}$ & I & $0.40 \%$ & $\begin{array}{l}\text { Healthcare } \\
\text { Resource } \\
\text { Group JD07K }\end{array}$ & 423.00 \\
\hline $\begin{array}{l}\text { Dermatology } \\
\text { related hospital } \\
\text { admissions in } \\
\text { patients with } \\
\text { moderate/ } \\
\text { severe AD }\end{array}$ & 0.14 & $100.00 \%$ & $\begin{array}{l}\text { Healthcare } \\
\text { Resource } \\
\text { Group JD07K }\end{array}$ & 423.00 \\
\hline $\begin{array}{l}\text { Primary care } \\
\text { visits in patients } \\
\text { with moderate/ } \\
\text { severe AD }\end{array}$ & 17.72 & $\begin{array}{l}100 \% \text { (Flare- } \\
\text { up) }\end{array}$ & $\begin{array}{l}\text { GP } \\
\text { consultation }\end{array}$ & 38.00 \\
\hline $\begin{array}{l}\text { Dermatology } \\
\text { clinic outpatient } \\
\text { visits in patients } \\
\text { with moderate/ } \\
\text { severe AD }\end{array}$ & 7.53 & $\begin{array}{l}100 \% \\
\text { (Flare up) }\end{array}$ & $\begin{array}{l}\text { Dermatology } \\
\text { outpatient } \\
\text { clinic }\end{array}$ & 56.00 \\
\hline $\begin{array}{l}\text { Sick leave in } \\
\text { patients with } \\
\text { mild AD (days/ } \\
\text { year) }\end{array}$ & 0.1 & 100 & $\begin{array}{l}\text { Median } \\
\text { weekly gross } \\
\text { earnings }\end{array}$ & 569.00 \\
\hline $\begin{array}{l}\text { Sick leave in } \\
\text { patients with } \\
\text { moderate AD } \\
\text { (days/year) }\end{array}$ & I.I & 100 & $\begin{array}{l}\text { Median } \\
\text { weekly gross } \\
\text { earnings }\end{array}$ & 569.00 \\
\hline $\begin{array}{l}\text { Absenteism } \\
\text { (hours) }\end{array}$ & $\begin{array}{l}2(\mathrm{~h} / \\
\text { visits })\end{array}$ & 100 & $\begin{array}{l}\text { Median } \\
\text { weekly gross } \\
\text { earnings }\end{array}$ & 569.00 \\
\hline
\end{tabular}

utility is 4.12 QALY being the treatment affecting the most the patient's quality of life, asserting the necessity of treatment in the case of $\mathrm{AD}$.

Emollients $\mathrm{C}$ and $\mathrm{D}$ are less effective than emollient $\mathrm{A}$ in each comparison.

\section{Costs}

Emollient B is the least expensive as shown in (Table 5). The expenses amount to $£ 1802.75$ with physician visit
Table 4 Out-of-pocket Expenditures, ECLA Study

\begin{tabular}{|l|l|l|l|l|}
\hline \multirow{2}{*}{ Item } & \multicolumn{3}{|l|}{ Maintenance } & \multicolumn{2}{l|}{ Flare-up } \\
\cline { 2 - 5 } & $\begin{array}{l}\text { Inflated } \\
\text { Price } \boldsymbol{\epsilon}\end{array}$ & $\begin{array}{l}\text { Frequency } \\
\%\end{array}$ & $\begin{array}{l}\text { Inflated } \\
\text { Price } \boldsymbol{\epsilon}\end{array}$ & $\begin{array}{l}\text { Frequency } \\
\%\end{array}$ \\
\hline Clothes & 39.39 & 2.8 & 82.30 & 19.2 \\
\hline Bandages & 34.33 & 5.3 & 49.69 & 25.2 \\
\hline $\begin{array}{l}\text { Hygiene } \\
\text { Products }\end{array}$ & 39.93 & 33.7 & 57.73 & 70.9 \\
\hline $\begin{array}{l}\text { Sun } \\
\text { Protection }\end{array}$ & 32.52 & 24.8 & 35.33 & 39.1 \\
\hline $\begin{array}{l}\text { Food } \\
\text { Supplement }\end{array}$ & 43.55 & 5.3 & 79.50 & 20.6 \\
\hline $\begin{array}{l}\text { Other } \\
\text { Products }\end{array}$ & 26.74 & 4.6 & 61.80 & 19.7 \\
\hline
\end{tabular}

being the main post of expenses (£1147.01). Moisturiser accounts only for $£ 262.18$ during the six-year period.

Emollient $\mathrm{A}$ is the second cheapest treatment. The expenses amount to $£ 1844.23$ for a six-year period. Physician visits are still the main cost of expenses (£1025.32) however; they are lower than the one with emollient B translating to better efficiency of emollient A.

Surprisingly, no emollient is more expensive than the two previous options, needing a hefty $£ 2251.01$ over the course of six-years. While the spending on moisturiser is kept to null, need of physician service are skyrocketing to $£ 1774.64$. The decrease in moisturiser spending is more than counterbalanced by the increase in physician needs.

The costs of the MD emollient $\mathrm{C}$ are much more important (£6337.85). The cost of moisturiser alone (£4410.95) is higher than all other treatments. This is due to the large increase in the emollient cost by $\mathrm{mL}$ and the need to use more emollient - one application more a day - to achieve a soothing effect. Cost of physician visits are raised, translating to a lower effectiveness.

Emollient D, while not as expensive as emollient C (£2822.69), is more expensive than emollients A and B. Emollient D needs almost $125 \mathrm{~g} /$ cycle more than emollient A to relieve the symptoms in a similar way, and costs almost the same $(0.033$ vs $0.032 £ / \mathrm{mL})$.

\section{Incremental Cost Effectiveness Ratio}

Emollient $\mathrm{A}$ is both more expensive and effective than emollient B. The difference in cost amounts to $£ 41.48$ and the difference in effectiveness is 0.097 YWFU. 
Table 5 Model Results, Effectiveness and Cost Details

\begin{tabular}{|c|c|c|c|c|c|}
\hline & Emollient A & No Moisturiser & Emollient B & Emollient C & Emollient D \\
\hline \multicolumn{6}{|l|}{ EFFICACY } \\
\hline Number of cycles in flare-up state & 10.63 & $|8.4|$ & 11.89 & 15.43 & 16.94 \\
\hline Number of cycles inmaintenance state & 59.75 & 51.98 & 58.49 & 54.95 & 53.45 \\
\hline Time without flare-ups & 4.58 & 3.99 & 4.49 & 4.22 & 4.10 \\
\hline QALY & 4.19 & 4.12 & 4.18 & 4.15 & 4.13 \\
\hline Percent of time in perfect health & $70 \%$ & $69 \%$ & $70 \%$ & $69 \%$ & $69 \%$ \\
\hline \multicolumn{6}{|l|}{ COST } \\
\hline Corticoid & $E \mid 32.42$ & $£ 229.26$ & $f \mid 48.15$ & $f 192.26$ & $£ 210.99$ \\
\hline Hospitalization & $E \mid 26.20$ & $f 151.50$ & $E|30.3|$ & $f|4| .83$ & $f \mid 46.72$ \\
\hline Physician visits & $£ 924.34$ & $£ \mid 600.33$ & $£ 1034.10$ & $f \mid 342.01$ & $£ \mid 472.75$ \\
\hline Medical Expenses (I) & fII 82.95 & $f 1981.09$ & $f|3| 2.55$ & $\{1676.09$ & $£ 1830.45$ \\
\hline Moisturiser & $£ 441.37$ & - & $£ 262.18$ & $£ 4410.95$ & $£ 731.76$ \\
\hline OOP expenses & $£ 219.90$ & $€ 269.2$ & $£ 228.02$ & $£ 250.81$ & $£ 260.48$ \\
\hline Ancillary Expenses (2) & $£ 661.27$ & $£ 269.92$ & $£ 490.21$ & $£ 4661.76$ & $£ 992.24$ \\
\hline Loss of productivity (3) & $£ 652.57$ & $f 1117.62$ & $€ 728.08$ & $£ 939.90$ & $£ 1029.85$ \\
\hline Total All Payer Perspective $(I+2)$ & $\{1844.23$ & $£ 2251.01$ & $£ \mid 802.75$ & $£ 6337.85$ & $£ 2822.69$ \\
\hline Total Societal Perspective $(I+2+3)$ & $£ 2496.80$ & $£ 3368.63$ & $£ 2530.83$ & $£ 7277.75$ & $£ 3852.54$ \\
\hline
\end{tabular}

Therefore, ICER is $£ 428.30 / Y W F U$ (Table 6). It will cost $£ 428.30$ for an additional year without flare-ups.

Emollient A is the dominant strategy compared to no treatment, 217 more days (about two-thirds of a year) without flare-ups and $£ 406.78$ cheaper. The other two strategies are dominated as well since they are both more expensive and less effective than emollient A.

The efficiency frontier (Figure 2) is composed only of the two efficient strategies: emollient B and emollient A. Every strategy figuring on the right of the efficiency frontier is considered inefficient. A cost-utility analysis was also implemented. The incremental cost utility ratio (ICUR) between emollient A and emollient B is $£ 3882.97 /$ QALY. The other strategies are dominated.

\section{Sensitivity Analysis}

Results of the deterministic sensitivity analysis are showed in Figure 3. The main causes of variability in the results are the probabilities of transition Mf. Unsurprisingly variation of the cost of products are an important source of variability regarding the cost of treatment. Other probabilities of transition are reasons of variability in the efficiency of the treatment.

For PSA we ran 1000 simulations. While comparing emollient $\mathrm{A}$ and no moisturiser, $100 \%$ of the simulations show emollient A as more effective. Figure 3A Emollient $\mathrm{A}$ is less expensive in $80 \%$ of the simulation, therefore the dominant strategy.

Comparing emollients $\mathrm{A}$ and $\mathrm{B}$ we found emollient A the dominant strategy $45 \%$ of the time (Figure $3 \mathrm{~B}$ ). Emollient $\mathrm{A}$ is costlier and more effective in $43 \%$ of the simulations and is dominated in $9 \%$. This confirms that emollient $\mathrm{A}$ is cost effective.

For a willingness to pay (WTP) below $£ 50$, a strategy figuring emollient $\mathrm{B}$ maximizes the net monetary benefit, with

Table 6 Cost Efficiency Results, Base-case

\begin{tabular}{|l|l|l|l|l|l|}
\hline Emollient & Costs $(\boldsymbol{t})$ & $\Delta \mathbf{C}(\boldsymbol{t})$ & Benefit (YWFU) & $\Delta B(Y W F U)$ & ICER ( $\boldsymbol{\epsilon} /$ YWFU) \\
\hline Emollient B & 1802.75 & & 4.487 & & \\
\hline Emollient A & 1844.23 & 41.48 & 4.584 & 0.097 & 428.30 \\
\hline No moisturiser & 2251.01 & 406.78 & 3.987 & -0.596 & Dominated \\
\hline Emollient D & 2822.69 & 978.46 & 4.100 & -0.484 & Dominated \\
\hline Emollient C & 6337.85 & 4493.62 & 4.215 & -0.369 & Dominated \\
\hline
\end{tabular}




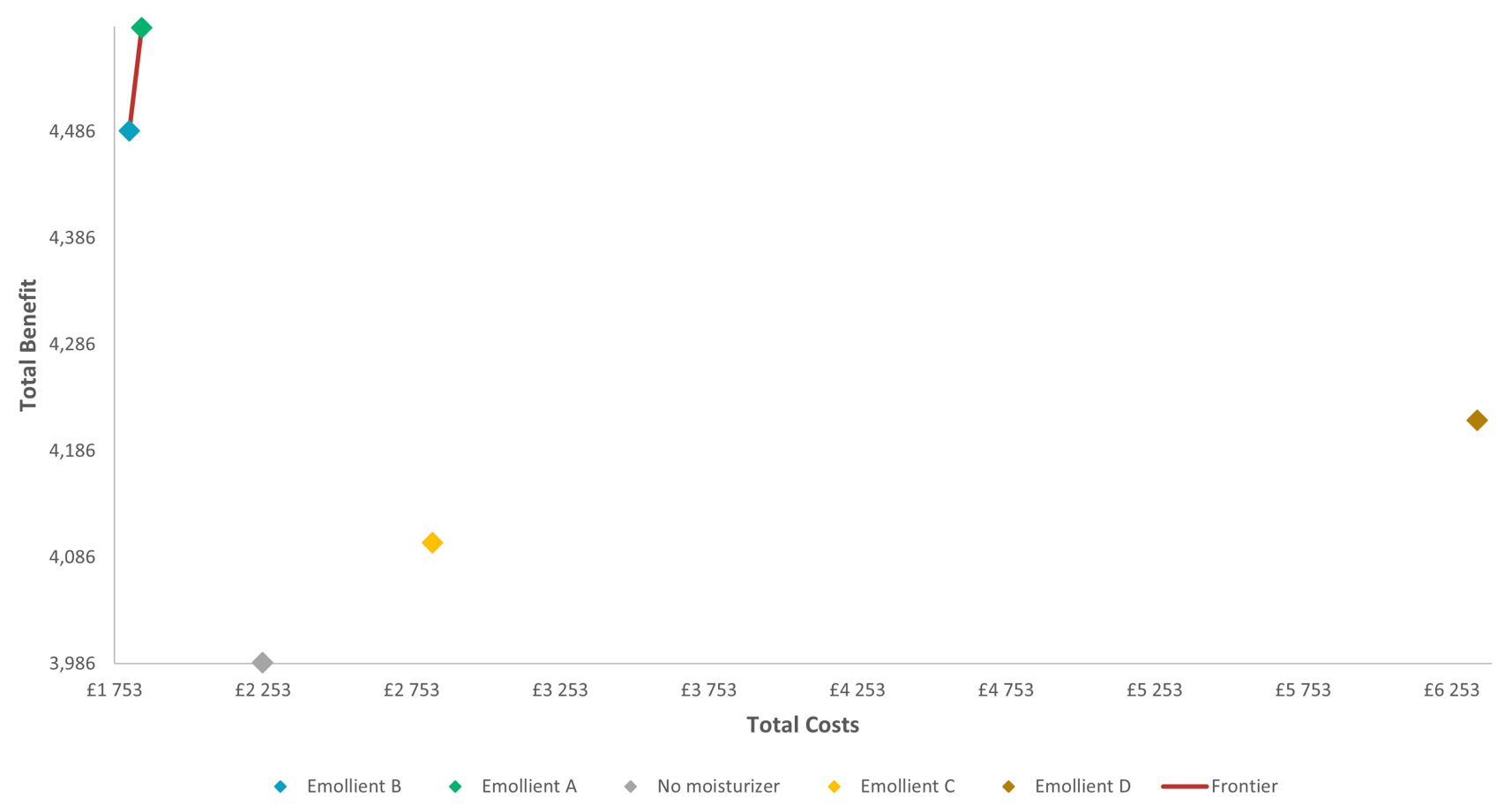

Figure 2 Efficiency frontier of cost-effectiveness of different strategies in AD treatment.

a probability of $48 \%$ (Figure 4). From $£ 200$ and upwards emollient A maximizes the net monetary benefit and has the highest probability of being cost-effective. For a WTP of $£ 8000$, emollient A has a probability of being cost effective of $81 \%$.

The no moisturiser strategy has a probability of $9 \%$ of being cost-effective when the willingness to pay is $£ 0$, it rapidly decreases to $2 \%$ for a WTP of $£ 500$. Strategies using the other two moisturisers are never efficient regardless of the WTP.

In a sensitivity analysis, we modified the time horizon and used a one-year time horizon: emollient $\mathrm{A}$ is always the most effective ( 0.84 YWFU) compared to emollient B ( 0.82 YWFU) and no moisturiser (0.73 YWFU). Emollient B is still the cheapest strategy ( $£ 316.89$ against $£ 324.97$ for emollient A). In this analysis, the ICER is increased to $£ 471.37 /$ YWFU. No moisturiser is dominated (£397.07).

This perspective was completed by a societal perspective with the loss of productivity accounted for. In this context we found the A emollient to be the cheapest (£2496.80) (Table 5) and the most effective strategy, thus dominating all the other strategies. The better effectiveness of emollient A allowed less visits to the GP resulting in less productivity losses, thus making this strategy dominant.

\section{Discussion}

To our knowledge, this study is the first cost-effectiveness analysis of emollients. We tried to bring concepts usually used within the drugs to skin care products. The National Health Service (NHS) perspective was not adopted as no public insurance is willing to pay for emollients, therefore our option was to choose the health care system and the societal point of view.

The distinctions made in the study allows a good understanding of the different costs in the treatment of AD. The societal perspective is the most thorough and adapted to a study like this one. Indeed, multiple aspects of $\mathrm{AD}$ are often silenced. The hidden out-of-pocket costs of AD such as clothes and skin care products (ie cleanser, moisturisers) should necessarily be accounted for. Moreover, the productivity losses due to absenteeism should be accounted for. They reflect the reality of caring parents of children suffering from $\mathrm{AD}$ and the difficulties faced by adults suffering from $\mathrm{AD}$ in the workplace. Overall data are sparse. Most data come from expert dermatologist's opinions, or from short duration clinical trials.

Therefore, hypotheses made in this study are limited (seldom strong). Nevertheless, hypotheses were thoroughly tested in the sensitivity analysis and the base case scenario conclusions were not called into question.

In order to get closer to the UK market and although methodologically there are some differences between Cetraben cream and Doublebase gel, some of the most commonly used products on this market, when compared to 


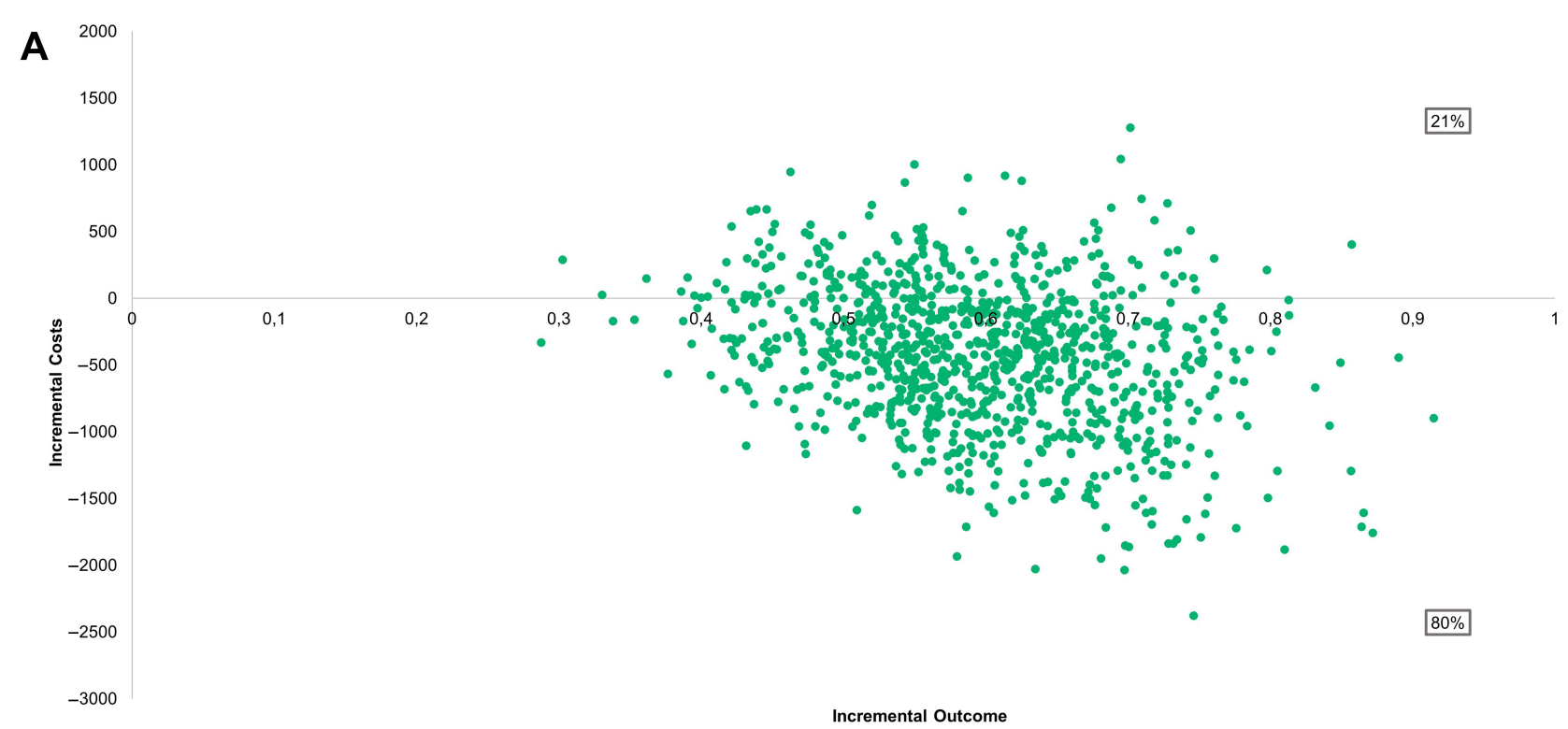

\section{B}

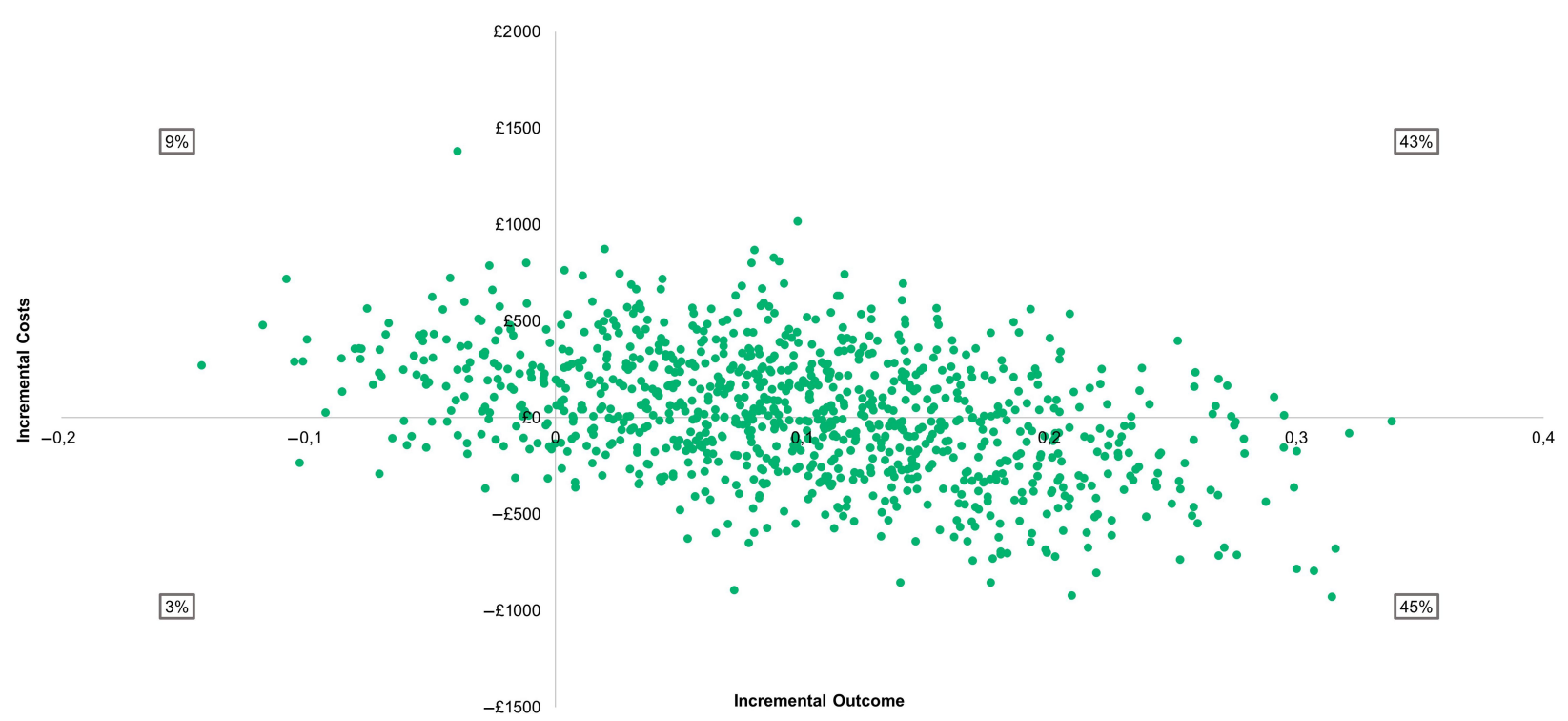

Figure 3 Probabilistic sensitivity analysis. (A) Emollient A vs no moisturizer, (B) Emollient A vs emollient B.

emollient B (not strictly equivalent to the former in their quantitative composition of each ingredient), the ingredients are indeed similar. One of the main active ingredients in these three products is glycerol, hence, with careful interpretation, we still want to remember those comparators relevant to the UK market. As emollient B is not widely distributed (despite being available on the UK market), we have included those two similar available comparators. While the composition is the same qualitatively, quantitatively it may differ and impact the efficacy. High performance liquid chromatography should be used to generalize the results. Nevertheless, we can assume that they will show similar QALY and similar efficacy with the same quantity/application and daily application as emollient B. In terms of price, price of Doublebase and Cetraben per g were $£ 0.01166$ and $£ 0.01198$, respectively which is similar to the price for emollient B ( $£ 0.0121)$. We can assume that Cetraben and Doublebase would probably show similar ICER as emollient $B$ if it were to be involved in the study, which again emphasize that emollient A is still more expensive and more efficient.

We also assumed that transition probabilities were the same for Mf and Pf given the lack of data. Experts asserts there is a difference, perhaps a rebound effect. However, this effect is not yet quantified, therefore it was impossible to construct the 


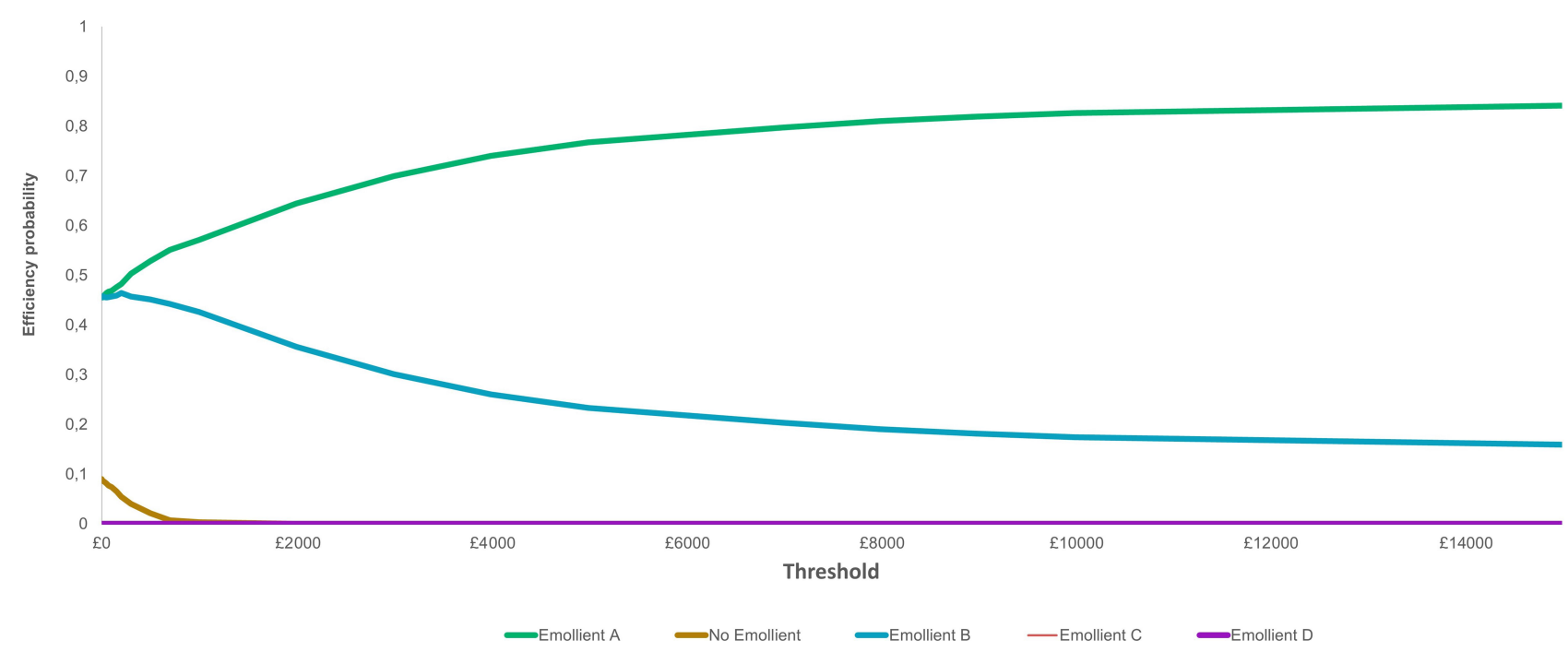

Figure 4 Acceptability curves of different treatment strategy in AD.

model using this assumption. It would be necessary to realize a study where patients are followed for more than four weeks.

Emollients A and B have similar effectiveness. Still emollient A has the edge over emollient $B$ in the base-case scenario and in most probabilistic sensitivity analysis. Overall emollient A is the most effective in relieving $\mathrm{AD}$ symptoms in our comparison.

Regarding quality of life, this model does not consider the benefits that most differentiate emollients from their moisturizing capacity. The number of daily applications while they are taken in the price computation are a burden to the quality of life and not accounted for. The cosmetic properties can also be considered. If the emollient does not dry or be absorbed quickly enough it will be more difficult to dress after use. This consideration is not well measured yet and can potentially increase the gap between the different emollients efficacy.

In regards of costs, the main expenditure item is the physicians's consultations. These hidden costs should be accounted for in the prescription of an emollient. The studied emollient is the one with the smaller number of consultations (less cost). While no moisturiser is the less costly option regarding emollients expenditure, the cost for the society is high as most of cost of treatment came from consultations.

Emollient $\mathrm{A}$ is more expensive and more efficient. Over a six-year period the $£ 428.30$ /YWFU ICER shows that while it is costlier than the mass market emollient $\mathrm{B}$ it is not that much more expensive.

The no moisturiser option was necessary to investigate. While it is deemed as the less costly treatment by the general population, in the end it is more expensive than emollient $\mathrm{A}$ or $\mathrm{B}$. This confirms that the main costs in the AD treatment are not the obvious one, questioning the policy of no reimbursement of moisturiser from the mandatory health insurance. Even though for a WTP of $£ 0$, no moisturiser is not the most probable efficient strategy.

Emollients A and B are composing the efficiency frontier and dominating all the other clinical options. Even given the stated weakness of the model, further investigations should be done to allow better care. Today, given the ever-shrinking health assurance budgets the most efficient treatment should be accounted for.

\section{Disclosure}

Elise Cabout, Robert Launois, and Sebastien Eymere (REES France) report grants from La Roche-Posay. Charles Taïeb has served as a consultant for L'Oreal/La Roche-Posay. Flavia Aslanian reports personal fees from L'Oréal, during the conduct of the study. Sophie Seité is an employee of La Roche-Posay, France. The authors report no other conflicts of interest in this work.

\section{References}

1. Williams H, Robertson C, Stewart A, et al. Worldwide variations in the prevalence of symptoms of atopic eczema in the international study of asthma and allergies in childhood. J Allergy Clin Immunol. 1999;103 (1):125-138. doi:10.1016/S0091-6749(99)70536-1

2. Lavery M, Stull C, Kinney M, Yosipovitch G. Nocturnal pruritus: the battle for a peaceful night's sleep. Int $J$ Mol Sci. 2016;17(3):425. doi: $10.3390 / \mathrm{ijms} 17030425$

3. Ma L, Li P, Tang J, et al. Prolonging time to flare in pediatric atopic dermatitis: a randomized, investigator-blinded, controlled, multicenter clinical study of a ceramide-containing moisturizer. Adv Ther. 2017;34 (12):2601-2611. doi:10.1007/s12325-017-0640-6

4. Wirén $\mathrm{K}$, Nohlgård $\mathrm{C}$, Nyberg $\mathrm{F}$, et al. Treatment with a barrier-strengthening moisturizing cream delays relapse of atopic dermatitis: a prospective and randomized controlled clinical trial. $J$ Eur Acad Dermatol Venereol JEADV. 2009;23(11):1267-1272. doi:10.1111/ j.1468-3083.2009.03303.x 
5. van Zuuren EJ, Fedorowicz Z, Christensen R, Lavrijsen AP, Arents BW. Emollients and moisturisers for eczema. Cochrane Database Syst Rev. 2017. doi:10.1002/14651858.CD012119.pub2

6. NICE. The guidelines manual | guidance and guidelines. NICE; Published 2012. Available from: https://www.nice.org.uk/process/ pmg6/chapter/assessing-cost-effectiveness\#ftn.footnote_14. Accessed January 14, 2019.

7. Hjalte F, Asseburg C, Tennvall GR. Cost-effectiveness of a barrierstrengthening moisturizing cream as maintenance therapy vs. no treatment after an initial steroid course in patients with atopic dermatitis in Sweden-with model applications for Denmark, Norway and Finland. J Eur Acad Dermatol Venereol JEADV. 2010;24(4):474-480. doi:10.1111/j.1468-3083.2009.03449.x

8. Hjelmgren J, Svensson A, Jörgensen ET, Lindemalm-Lundstam B, Ragnarson Tennvall G. Cost-effectiveness of tacrolimus ointment vs. standard treatment in patients with moderate and severe atopic dermatitis: a health-economic model simulation based on a patient survey and clinical trial data. Br J Dermatol. 2007;156(5):913-921. doi:10.1111/j.1365-2133.2006.07707.x

9. Seite S, Zelenkova H, Martin R. Clinical efficacy of emollients in atopic dermatitis patients \&ndash; relationship with the skin microbiota modification. Clin Cosmet Investig Dermatol. 2017;10:25-33. doi:10.2147/CCID.S121910

10. Beck R, Pauker SG. Does DEALE-ing stack the deck? Med Decis Making. 1999:503-504.

11. Kim JP, Chao LX, Simpson EL, Silverberg JI. Persistence of atopic dermatitis (AD): a systematic review and meta-analysis. $\mathrm{J} \mathrm{Am} \mathrm{Acad}$ Dermatol. 2016;75(4):681-687.e11. doi:10.1016/j.jaad.2016.05.028

12. Naimark DMJ, Bott M, Krahn M. The half-cycle correction explained: two alternative pedagogical approaches. Med Decis Making. 2008;28(5):706-712. doi:10.1177/0272989X08315241

13. National Institute of Health and Care Excellence (NICE). Guide to the methods of technology appraisal 2013. 2013.

14. Seite S, Zelenkova H, Martin R. Clinical efficacy of emollients in atopic dermatitis patients - relationship with the skin microbiota modification. Clin Cosmet Investig Dermatol. 2017;10:25-33.

15. Angelova-Fischer I, Rippke F, Richter D, et al. Stand-alone emollient treatment reduces flares after discontinuation of topical steroid treatment in atopic dermatitis: a double-blind, randomized, vehicle-controlled, left-right comparison study. Acta Derm Venereol. 2018;98(5):517-523. doi: $10.2340 / 00015555-2882$
16. Tiplica GS, Boralevi F, Konno P, et al. The regular use of an emollient improves symptoms of atopic dermatitis in children: a randomized controlled study. J Eur Acad Dermatol Venereol JEADV. 2018;32(7):1180-1187. doi:10.1111/jdv.14849

17. Office for National Statistics. Inflation and price indices - office for national statistics. Published 2019. Available from: https://www.ons. gov.uk/economy/inflationandpriceindices. Accessed March 12, 2019.

18. NHS. Prescription cost analysis - England, 2017 [PAS]. NHS Digital; Published 2017. Available from: https://digital.nhs.uk/data-andinformation/publications/statistical/prescription-cost-analysis/prescrip tion-cost-analysis-england-2017. Accessed February 20, 2019.

19. NHS. Prescription cost analysis - England, 2018 [PAS]. NHS Digital; Published 2018. Available from: https://digital.nhs.uk/data-andinformation/publications/statistical/prescription-cost-analysis/prescrip tion-cost-analysis-england-2017. Accessed February 20, 2019.

20. Åkerström U, Reitamo S, Langeland T, et al. Comparison of moisturizing creams for the prevention of atopic dermatitis relapse: a randomized double-blind controlled multicentre clinical trial. Acta Derm Venereol. 2015;95(5):587-592. doi:10.2340/00015555-2051

21. Salisbury C, O'Cathain A, Thomas C, et al. National average unit costs for primary care and personal social services. NIHR Journals Library; 2017. Available from: https://www.ncbi.nlm.nih.gov/books/ NBK409325/. Accessed February 19, 2019.

22. NHS England, NHS Improvement. 2017/18 and 2018/19 national tariff payment system. 2018:120.

23. Taieb DC. ECLA Rapport statistique. 2017:105.

24. Launois R, Ezzedine K, Cabout E, et al. Importance of out-of-pocket costs for adult patients with atopic dermatitis in France. J Eur Acad Dermatol Venereol. 2019;33:1921-1927. doi:10.1111/jdv.15581

25. Norrlid H, Hjalte F, Lundqvist A, Svensson A, Ragnarson Tennvall G. Cost-effectiveness of maintenance treatment with a barrier-strengthe-ning moisturizing cream in patients with atopic dermatitis in Finland, Norway and Sweden. Acta Derm Venereol. 2016;96(2):173-176.
Clinical, Cosmetic and Investigational Dermatology is an international, peer-reviewed, open access, online journal that focuses on the latest clinical and experimental research in all aspects of skin disease and cosmetic interventions. This journal is indexed on CAS.
The manuscript management system is completely online and includes a very quick and fair peer-review system, which is all easy to use. Visit http://www.dovepress.com/testimonials.php to read real quotes from published authors. 